\title{
Probiotic supplementation influences faecal short chain fatty acids in infants at high
}

\section{risk for eczema}

\author{
H.K. Kim ${ }^{1,2}$, N.B.M.M. Rutten ${ }^{3}$, I. Besseling-van der Vaart ${ }^{2}$, L.E.M. Niers ${ }^{4}$, Y.H. Choi ${ }^{*}$, G.T. Rijkers ${ }^{5,6}$ and $^{2}$ \\ S. van Hemert ${ }^{2 *}$ \\ ${ }^{1}$ Natural Product Laboratory, Institute of Biology, Leiden University, P.O. Box 9502, 2300 RA Leiden, the Netherlands; \\ ${ }^{2}$ Winclove Probiotics, Hulstweg 11, 1032 LB Amsterdam, the Netherlands; ${ }^{3}$ Department of Paediatrics, St. Antonius Hospital, \\ P.O. Box 2500, 3430 EM Nieuwegein, the Netherlands; ${ }^{4}$ Department of Paediatrics, Maxima Medical Center, P.O. Box 7777, \\ $5500 \mathrm{MB}$ Veldhoven, the Netherlands; ${ }^{5}$ Department of Medical Microbiology and Immunology, St. Antonius Hospital, P.O. \\ Box 2500, 3430 EM Nieuwegein, the Netherlands; ${ }^{6}$ Science Department, University College Roosevelt, Lange Noordstraat 1, \\ 4330 AB Middelburg, the Netherlands; y.choi@chem.leidenuniv.nl; s.vanhemert@winclove.nl
}

Received: 2 May 2015 / Accepted: 22 August 2015

(c) 2015 Wageningen Academic Publishers

\section{RESEARCH ARTICLE}

\begin{abstract}
The composition of the gut microbiota plays a role in the development of allergies. Based on the immunomodulating capacities of bacteria, various studies have investigated the potential role for probiotics in the prevention of childhood eczema. In a previous study we have shown that significantly less children developed eczema after probiotic supplementation (Bifidobacterium bifidum W23, Bifidobacterium animalis subsp. lactis W52 and Lactococcus lactis W58, Ecologic ${ }^{\circ}$ Panda) at three months of age as compared to controls. Here, metabolites in faecal samples of these 3-month old children were measured by ${ }^{1} \mathrm{H}$-nuclear magnetic resonance to investigate possible gut metabolic alterations. Lower amounts of short-chain fatty acids (SCFAs), succinate, phenylalanine and alanine were found in faecal samples of children later developing eczema, whereas the amounts of glucose, galactose, lactate and lactose were higher compared to the children not developing eczema. Although these differences were already present at the age of 3 months, eczema did not develop in the majority of children before the age of 1 year. Supplementation of multispecies probiotics seems to induce higher levels of lactate and SCFAs, and lower levels of lactose and succinate when compared with the placebo group. This might explain the temporary preventive effect of probiotics on the development of eczema. These results highlight the role bacterial metabolites may play in development of the immune system, even before clinical manifestations of allergic disease arise.
\end{abstract}

Keywords: atopy, intestinal microbiota, metabolites, probiotics

\section{Introduction}

The worldwide prevalence of allergic diseases such as eczema, food allergy, asthma and allergic rhinitis has increased considerably in the past few decades (Fishbein and Fuleihan, 2012; Ismail et al., 2013). Up to 40\% of the population of the USA and Europe suffer from at least one type of allergy and the prevalence of allergies in industrial societies has doubled over the past 15 years (Kramer et al., 2013). Amongst these, eczema is one of the most common inflammatory skin diseases in childhood. The aetiology of allergic diseases is unknown although it has been well established that both genetic and environmental factors do play a role. There is growing evidence that the composition of gut microbiota is a crucial environmental factor in the development of allergic disease. The development of allergies has been linked to reduced microbial exposure in early childhood, reduced bacterial diversity and an altered composition of gut microbiota (Abrahamsson et al., 2014; Bisgaard et al., 2011; Bjorksten et al., 2001; Kramer et al., 2013). In this context, the window of opportunity for influencing the composition of the intestinal microbiota and possibly modulate the development of allergic diseases, would be the perinatal period. 
The composition of the gut microbiota in infants is influenced by several environmental factors, including mode of delivery, nutrition, medication, such as antibiotics and by the supplementation of pre- and probiotics (Quigley, 2013). Probiotics are living microorganisms that, when administered in adequate amounts, confer a beneficial health effect on the host (FAO/WHO, 2001; Hill et al., 2014). The most widely used probiotic bacteria belong to the Lactobacillus and Bifidobacterium genera. Certain probiotics have shown to be effective in the prevention and/or management of disorders such as necrotising enterocolitis, acute infectious diarrhoea, antibioticassociated diarrhoea, inflammatory bowel disease (pouchitis and ulcerative colitis) and lactose maldigestion (Floch et al., 2011; Sanders et al., 2013). Various studies have investigated the potential of probiotics, both for primary prevention and for treatment of eczema and other atopic diseases. Results are inconsistent; while some studies have shown a preventive effect of probiotics on the development of eczema, others showed no effects (Elazab et al., 2013; Panduru et al., 2015). This inconsistency could be explained by differences in study design, amount and duration of probiotic supply, and the strain-specific effects of probiotic bacteria. Moreover, the biological mechanisms involved in successful clinical outcome of probiotic supplementation on the prevention of eczema still remain unknown.

One of the potential mechanisms by which probiotic bacteria could regulate the development of the mucosal immune system is stimulation of the differentiation of naive T-cells towards T-helper 1 cells (Th1) or regulatory T-cells, thereby shifting the balance between Th1 and T-helper 2 cells (Th2). In our clinical trial (the Pandastudy; Niers et al., 2009), a mixture of three probiotic strains was administered to infants at high-risk for atopy, from birth onwards during the first year of life. The probiotics were also given to the mothers during the last 6 weeks of pregnancy. The selection of probiotic strains was based on the ability to down-regulate Th2 cytokine production in vitro and to induce regulatory T-cell cytokines (Niers et al., 2007). Clinical supplementation of the multi-species probiotic product proved to have a significant preventive effect on the development of eczema in high-risk children within the first three months of life (Niers et al., 2009). This clinical difference was maintained up to the age of two years, although it lost significance. Recently, the long-term outcomes of this intervention were published (Gorissen et al., 2014), showing that the beneficial effect was not extended to the age of 6 years and did not lead to the primary prevention of asthma, in accordance with other studies published so far (Azad et al., 2013).

The biological pathways that mediate the clinical effects of probiotics are still unclear and it remains to be demonstrated whether immunoregulatory properties are an important mechanism in vivo. In order to gain insight into the biological mechanisms underlying the clinical outcome of probiotics, an analysis of bacterial metabolites was made. To that end the faecal metabolic profiles of the eczema-prone children in the Panda-study were investigated. The aim of this study was to identify potential differences in gut metabolites between children at-risk for atopic disease, that later developed eczema and those that did not develop eczema. Out of the several techniques available for metabolic profiles, ${ }^{1} \mathrm{H}$ nuclear magnetic resonance (NMR) spectroscopy was used. The advantages of NMR are robustness, reproducibility and the absence of extensive sample preparation; a disadvantage is the lower sensibility compared to other metabolomics techniques like mass spectrometry (Brennan, 2008; Lindon et al., 2007; Marchesi et al., 2007; Nicholson et al., 2005). It thus has been demonstrated that the metabolite profiles of gut microbiota can be constructed by targeted profiling of NMR spectra (Jacobs et al., 2008; Yen et al., 2015).

\section{Materials and methods}

\section{Design of study}

A double blind, randomised, placebo-controlled trial as described in detail by Niers et al. (2009) was performed. Briefly, pregnant women and their offspring (with a positive family history of allergic disease) received either once sachet daily with $3 \mathrm{~g}$ probiotics (Ecologic ${ }^{\circ} \mathrm{Panda}$, Winclove Probiotics, the Netherlands) or a placebo during the last six weeks of pregnancy (mothers) and during the first 12 months after birth (infants). The probiotic product contained the bacterial strains Bifidobacterium bifidum W23, Bifidobacterium animalis subsp. lactis W52 and Lactococcus lactis W58, a total $1 \times 10^{9}$ cfu per strain per day). In total 123 participants were included (per protocol) in the clinical study (63 assigned to the placebo, 60 to the probiotic group). In the placebo group 52 participants and in the probiotic group 50 participants completed the 3 months clinical follow-up. Follow-up continued up to six years of age, investigating the clinical manifestation of eczema, IgE sensitisation and, in time, allergic rhinitis and asthma. Blood samples and faecal samples were collected at different time points during follow-up.

\section{Clinical outcomes}

Children were clinically examined at the age of 3, 12, 24 months and 6 years of age, as described previously (Gorissen et al., 2014; Niers et al., 2009). For the present study, we grouped the children according to the presence or absence of eczema till two years of age. Parental-reported eczema was defined as eczema reported by parents, in diaries that they were asked to complete weekly for complaints of eczema, infectious or atopic symptoms, feeding habits and use of medication. Doctor-diagnosed eczema was defined as clinical signs of eczema diagnosed by the family doctor or consulted physician at the time of visit to the doctor's office or outpatient clinic. 


\section{Faecal sample collection}

As the clinical effects were significantly different between the probiotic and the placebo group at three months of age, faecal samples of this time point were chosen to perform metabolite analysis on. The faecal samples $(n=34)$ were collected directly from the diapers by the parents and stored at $-20{ }^{\circ} \mathrm{C}$ until analysis. Only samples from children of whom complete information on disease development was recorded were analysed, resulting in a different number of samples for each group (Group A - placebo eczema, $n=9$; group $B$ - probiotic eczema, $n=9$; group $C$ - probiotic no eczema, $n=9$; group $D$ - placebo no eczema, $n=7$ ).

\section{Faecal sample extraction}

Faecal extracts were prepared by mixing $20 \mathrm{mg}$ of frozen faecal material with $1 \mathrm{ml}$ of phosphate buffered saline that consists of $1.9 \mathrm{mM} \mathrm{Na}_{2} \mathrm{HPO}_{4}, 8.1 \mathrm{mM} \mathrm{NaH}_{2} \mathrm{PO}_{4}$, $150 \mathrm{mM} \mathrm{NaCl}$ and $1 \mathrm{mM}$ TSP (sodium 3-(trimethylsilyl)propionate- $\mathrm{d}_{4}$ ) in $\mathrm{D}_{2} \mathrm{O}$ (Le Gall et al., 2011). After mixing thoroughly, samples were centrifuged $(17,000 \times g, 5 \mathrm{~min})$. The supernatant was filtered through a $0.2 \mu \mathrm{m}$ membrane filter and $600 \mu \mathrm{l}$ of the filtrate was transferred to a $5 \mathrm{~mm}$ NMR tube for analysis.

\section{Nuclear magnetic resonance analysis}

High resolution ${ }^{1} \mathrm{H}$-NMR spectra were recorded using a Bruker AV 600 spectrometer (Bruker, Karlsruhe, Germany). Sample temperature was controlled at $25^{\circ} \mathrm{C}$. Each spectrum consisted of 128 scans and noesypr $1 d$ presaturation sequence was used to suppress the water signal with low power selective irradiation at the water frequency during the recycle delay $(D 1=2 \mathrm{~s})$ and mixing time $(D 8=$ $0.15 \mathrm{~s})$. A $90^{\circ}$ pulse length of $8.2 \mu \mathrm{s}$ was set for all samples. ${ }^{1} \mathrm{H}$-NMR spectra were Fourier transformed $(\mathrm{LB}=0.3 \mathrm{~Hz}$ ). After zero filling, each spectrum was manually phased and baseline corrected using Topspin 3.0 software (Bruker). All resonances of metabolites were confirmed by comparison with reported data (Le Gall et al., 2011) or by 2D NMR spectroscopy (J-resolved, COSY and HMBC).

\section{Data analysis}

The AMIX software (Bruker) was used to reduce the ${ }^{1} \mathrm{H}$-NMR spectra to an ASCII file, with total intensity scaling. Bucketing or binning was performed and the spectral data were reduced to include regions of equal width (0.04 parts per million) equivalent to the region of $\delta 10.00-0.40$. The regions of $\delta 4.88-4.64$ were not included in the analysis because of the remnant $\mathrm{D}_{2} \mathrm{O}$ signal.

Due to the complexity of the NMR spectra, it was necessary to apply multivariate data analysis to explore differences between the groups. In this case, we applied orthogonal partial least squares-discriminant analysis (OPLS-DA) which is a supervised multiple regression analysis similar to PLS-DA, but by orthogonolising non-correlated variables (Bylesjo et al., 2006). Principal component analysis and orthogonal projection to latent structures-discriminant analysis were performed with the SIMCA-P+ software (v. 13.0, Umetrics, Umeå, Sweden). The individual short chain fatty acids were quantified and differences between the groups were tested by ANOVA as described previously (Monleon et al., 2009).

\section{Results}

NMR analysis was performed for 34 samples. One sample from the placebo eczema group showed signals corresponding to $\mathrm{N}$-acetyl-p-aminophenol (Acetaminophen ${ }^{\circ}$ ), probably administered as an analgesic or antipyretic drug. This sample was excluded from further data analyses. There were no significant differences in baseline characteristics between groups (Table 1).

A total of 33 faecal samples were classified according to the presence or absence of parental-reported eczema. In a number of cases the reported eczema was confirmed by a doctor (doctor's diagnosis) (Figure 1). Within the eczema group, consisting of 8 children who received placebo (Group A) and 9 children who received probiotics (Group B), the majority of children did not have eczema at the moment of stool sampling (3 months) but developed symptoms later

Table 1. Baseline characteristics of study participants.

\begin{tabular}{|c|c|c|c|c|c|c|}
\hline \multicolumn{2}{|c|}{ Group } & $\mathbf{n}$ & $\begin{array}{l}\text { Gestational age in weeks } \\
(\text { mean } \pm S D)^{\mathrm{a}}\end{array}$ & 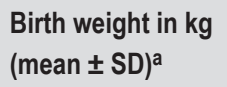 & $\begin{array}{l}\text { Mode of delivery } \\
\text { (caesarean section/total) }\end{array}$ & Feeding type \\
\hline A & Placebo, eczema & 8 & $40.5 \pm 1.8$ & $3.9 \pm 0.4$ & $2 / 8$ & 7 breast, 1 mixed \\
\hline B & Probiotics, eczema & 9 & $39.3 \pm 1.8$ & $3.4 \pm 0.4$ & $0 / 9$ & 5 breast, 2 bottle, 2 mixed \\
\hline C & Probiotics, no eczema & 9 & $40.5 \pm 1.7$ & $3.8 \pm 0.4$ & $1 / 9$ & 4 breast, 2 bottle, 3 mixed \\
\hline D & Placebo, no eczema & 7 & $40.0 \pm 1.4$ & $3.8 \pm 0.8^{b}$ & $0 / 7$ & 3 breast, 3 bottle, 1 mixed \\
\hline
\end{tabular}




\begin{tabular}{|c|c|c|c|c|}
\hline \multirow{9}{*}{ Placebo/eczema } & & $3 \mathrm{M}$ & $1 Y$ & $2 Y$ \\
\hline & 1 & $\Delta$ & $\Delta$ & $\mathbb{P}$ \\
\hline & 2 & $\mathbb{\nabla}$ & $\mathbb{\nabla}$ & $\mathbb{\nabla}$ \\
\hline & 3 & $\Delta$ & $\mathbb{N}$ & $\mathbb{N}$ \\
\hline & 4 & $\mathbb{R}$ & $\mathbb{\nabla}$ & $\Delta$ \\
\hline & 5 & $\mathbb{R}$ & $\mathbb{A}$ & $\Delta$ \\
\hline & 6 & $\Delta$ & $\Delta$ & $\Delta$ \\
\hline & 7 & $\mathbb{\nabla}$ & $\Delta$ & $\Delta$ \\
\hline & 8 & $\Delta$ & $\Delta$ & $\Delta$ \\
\hline \multirow[t]{9}{*}{ Probiotics/eczema } & 1 & $\mathbb{N}$ & $\Delta$ & $\Delta$ \\
\hline & 2 & $\Delta$ & $\Delta$ & $\Delta$ \\
\hline & 3 & $\mathbb{\nabla}$ & $\Delta$ & $\mathbb{N}$ \\
\hline & 4 & $\Delta$ & $\Delta$ & $\Delta$ \\
\hline & 5 & $\mathbb{N}$ & $\Delta$ & $\Delta$ \\
\hline & 6 & $\Delta$ & $\Delta$ & $\Delta$ \\
\hline & 7 & $\Delta$ & $\Delta$ & $\Delta$ \\
\hline & 8 & $\triangle$ & $\Delta$ & $\triangle$ \\
\hline & 9 & $\Delta$ & $\Delta$ & $\Delta$ \\
\hline
\end{tabular}

Figure 1. Overview of the eczema score of the participants. A missing triangle means that no information was available on doctor's diagnosed eczema.

Open lower triangles: no parental reported eczema; closed lower triangles: parental reported eczema; open upper triangles: no doctor's diagnosed eczema; closed upper triangle: doctor's diagnosed eczema

(Figure 1). In the non-eczema group (Group $\mathrm{C}$ - probiotics, $\mathrm{n}=9$; and group $\mathrm{D}$ - placebo, $\mathrm{n}=7$ ), none of the children showed clinical signs of eczema at any of the time points indicated.

\section{Differences in faecal metabolites between the eczema and non-eczema group}

${ }^{1} \mathrm{H}$-NMR spectroscopy of faecal extracts revealed the presence of various metabolites, such as lactate, short chain fatty acids (SCFAs) (butyrate, propionate, acetate), amino acids (alanine, valine, leucine, phenylalanine), sugars (glucose, galactose, xylose) and sugar alcohol (glycerol). The major identified metabolites and its chemical shifts found in faecal samples are listed in Table 2.

Comparison of the ${ }^{1} \mathrm{H}$-NMR spectra, analysed by OPLSDA, showed separation of the groups based on presence or absence of parental reported eczema $\left(\mathrm{R}^{2}=0.7, \mathrm{Q}^{2}=0.013\right.$; Figure $2 \mathrm{~A})$. The $R^{2}$ value estimates the goodness of fit, whereas the $Q^{2}$ value is a measure of the quality in multivariate models. $\mathrm{A}^{2}$-value $>0.5$ is considered large, so our observed differences were relatively small. Lower
Table 2. Chemical shifts of metabolites found in faecal samples.

\begin{tabular}{|c|c|}
\hline Metabolite & Chemical shift $(\delta)^{1}$ \\
\hline$n$-butyrate & $0.90(\mathrm{t}), 1.56(\mathrm{~m}), 2.16(\mathrm{t})$ \\
\hline Isovalerate & $0.91(d), 2.06(d)$ \\
\hline Isoleucine & $0.95(t), 1.02(d)$ \\
\hline Leucine & $0.96(d), 0.97(d)$ \\
\hline Valine & $1.00(d), 1.05(d)$ \\
\hline Propionate & $1.06(t), 2.19(q)$ \\
\hline Lactate & $1.33(d), 4.11(q)$ \\
\hline Threonine & $1.33(\mathrm{~d}), 4.26(\mathrm{~m})$ \\
\hline Isobutyrate & 1.07 (d), $2.39(\mathrm{~m})$ \\
\hline Alanine & $1.48(\mathrm{~d}), 3.79(\mathrm{q})$ \\
\hline Acetate & $1.92(s)$ \\
\hline Glutamate & $2.11(\mathrm{~m}), 2.36(\mathrm{~m}), 3.76(\mathrm{dd})$ \\
\hline Lysine & $1.48(\mathrm{~m}), 1.73(\mathrm{~m}), 1.91(\mathrm{~m}), 3.03(\mathrm{t}), 3.77(\mathrm{t})$ \\
\hline Aspartate & $2.68(\mathrm{dd}), 2.82(\mathrm{dd}), 3.90(\mathrm{dd})$ \\
\hline Succinate & $2.42(s)$ \\
\hline Trimethylamine & $2.91(\mathrm{~s})$ \\
\hline Taurine & $3.27(\mathrm{t}), 3.44(\mathrm{t})$ \\
\hline a-glucose & $5.24(d), 3.53(d d)$ \\
\hline$\beta$-glucose & 4.65 (d), 3.25 (dd) \\
\hline Glycine & $3.57(\mathrm{~s})$ \\
\hline Fumarate & $6.52(s)$ \\
\hline Uracil & $7.54(d), 5.80(d)$ \\
\hline Phenylalanine & $7.44(\mathrm{~m}), 7.38(\mathrm{~m}), 7.32(\mathrm{~d})$ \\
\hline Tyrosine & $7.20(d), 6.90(d)$ \\
\hline 4-hydroxyphenylacetate & $7.19(\mathrm{~d}), 6.86(\mathrm{~d}), 3.44(\mathrm{~s})$ \\
\hline Formate & $8.45(s)$ \\
\hline Adenine & $8.23(\mathrm{~s}), 8.19$ (s) \\
\hline a-galactose & 5.27 (d) \\
\hline$\beta$-galactose & 4.59 (d) \\
\hline$a-x y l o s e$ & $5.20(d)$ \\
\hline$\beta$-xylose & $4.58(d)$ \\
\hline Glycerol & 3.57 (dd), $3.67(\mathrm{dd}), 3.79(\mathrm{~m})$ \\
\hline Lactose & $5.22(d), 4.46(d), 4.67(d)$ \\
\hline
\end{tabular}

amounts of SCFAs (butyrate, acetate), alanine, succinate, and phenylalanine were detected in the faecal samples of the eczema group, whereas the amounts of glucose, galactose, lactose and lactate were higher in the eczema group when compared to the non-eczema group (Figure 2B). As expected with the low Q-value we observed, groups could not be discriminated based on a single metabolite, as displayed by the non-significant differences between groups (Table 3 ).

For 21 out of 33 children (64\%) of whom data on parental reported eczema were available, there was a corresponding doctor's diagnosis. A separate OPLS-DA analysis for eczema 
A

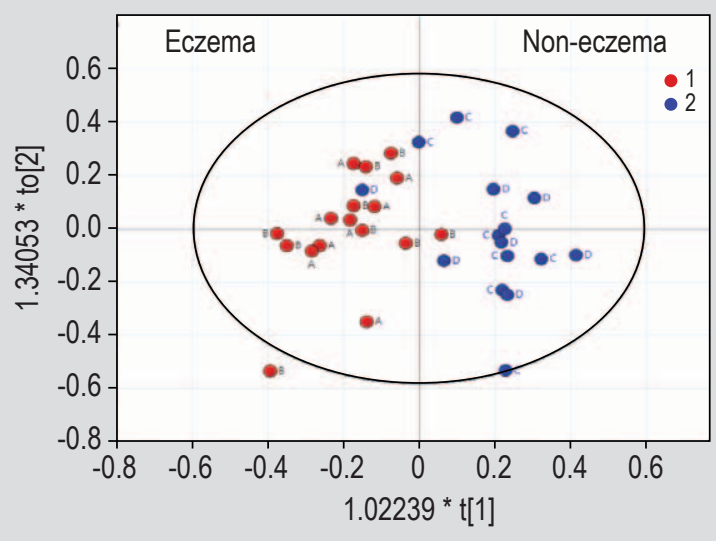

B

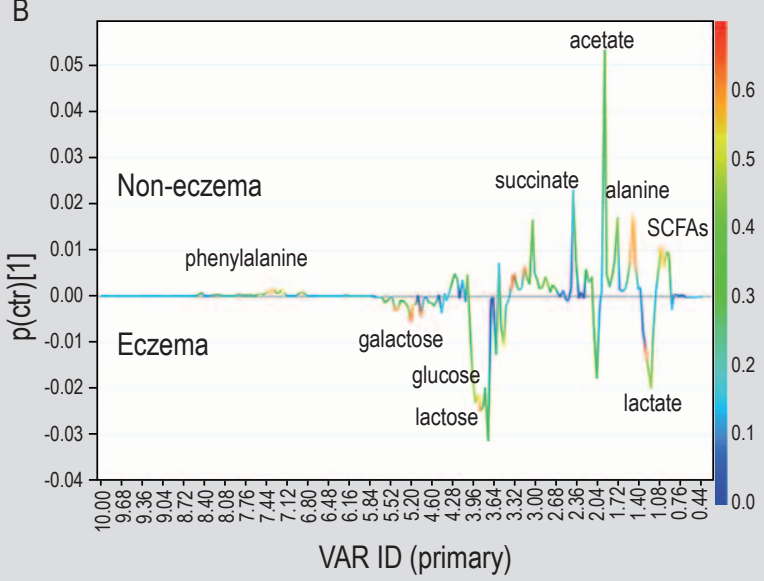

Figure 2. Orthogonal partial least squares-discriminant analysis of faecal samples between eczema group (group $A+B$, $n=17$, red circles [1]) and non-eczema group (group $C+D, n=16$, blue circles [2]), based on parental reported eczema. (A) Scatter plot; (B) S-line plot. $R^{2} Y=0.691, Q^{2} Y=0.013$.

Table 3. Concentrations short chain fatty acids (SCFAs) for the different groups. ${ }^{1}$

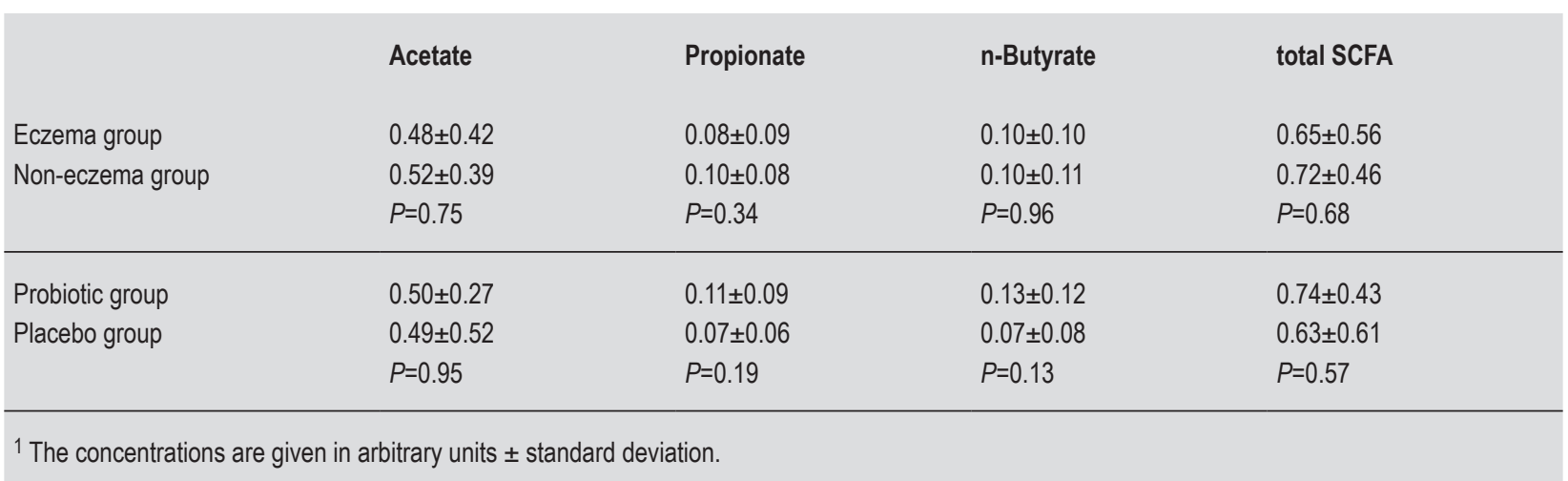

versus non-eczema based on doctor's diagnosis did not show significant differences $\left(Q^{2}\right.$-value negative, data not shown).

\section{Effects of probiotic supplementation on faecal metabolite composition}

To determine the effect of probiotic supplementation on identification of specific gut metabolites, we analysed the metabolic profiles of the probiotic and placebo group. In OPLS-DA, the probiotic group could be separated from the placebo group $\left(\mathrm{R}^{2}=0.7, \mathrm{Q}^{2}=0.3\right.$; Figure $\left.3 \mathrm{~A}\right)$. The probiotic group showed higher levels of lactate and SCFAs (acetate, butyrate, propionate, isobutyrate) and lower levels of lactose and succinate (Figure 3B).

\section{Discussion}

SCFAs were found to be the major discriminating metabolites between infants at-risk for developing atopy, expressed as eczema. Some SCFAs, mainly acetate, propionate and butyrate, are end-products of the breakdown of carbohydrates by gut microbial action. Among the SCFAs, butyrate is important for maintaining a normal colonocyte population (Topping and Clifton, 2001). Moreover, it has anti-inflammatory properties by the reduction of different pro-inflammatory cytokine expression and signalling, induction of nitric oxide synthesis and metalloproteinases, and the reduction and activation of lymphocyte proliferation (Leonel and Alvarez-Leite, 2012).

The potential role of SCFAs in eczema has been addressed before: Bottcher et al. (2000) showed lower levels of different SCFAs as compared with non-allergic controls in one-year old allergic children. Another study showed the severity of eczema to be inversely correlated with the amount of butyrate producing bacteria (Nylund et al., 2015). In our study, the eczema group consisted of children that developed eczema in the first two years of life. By analysing the 3 month-old samples, when the majority of children had not yet developed eczema, the demonstrated low levels of SCFAs seem to precede the clinical manifestation of 

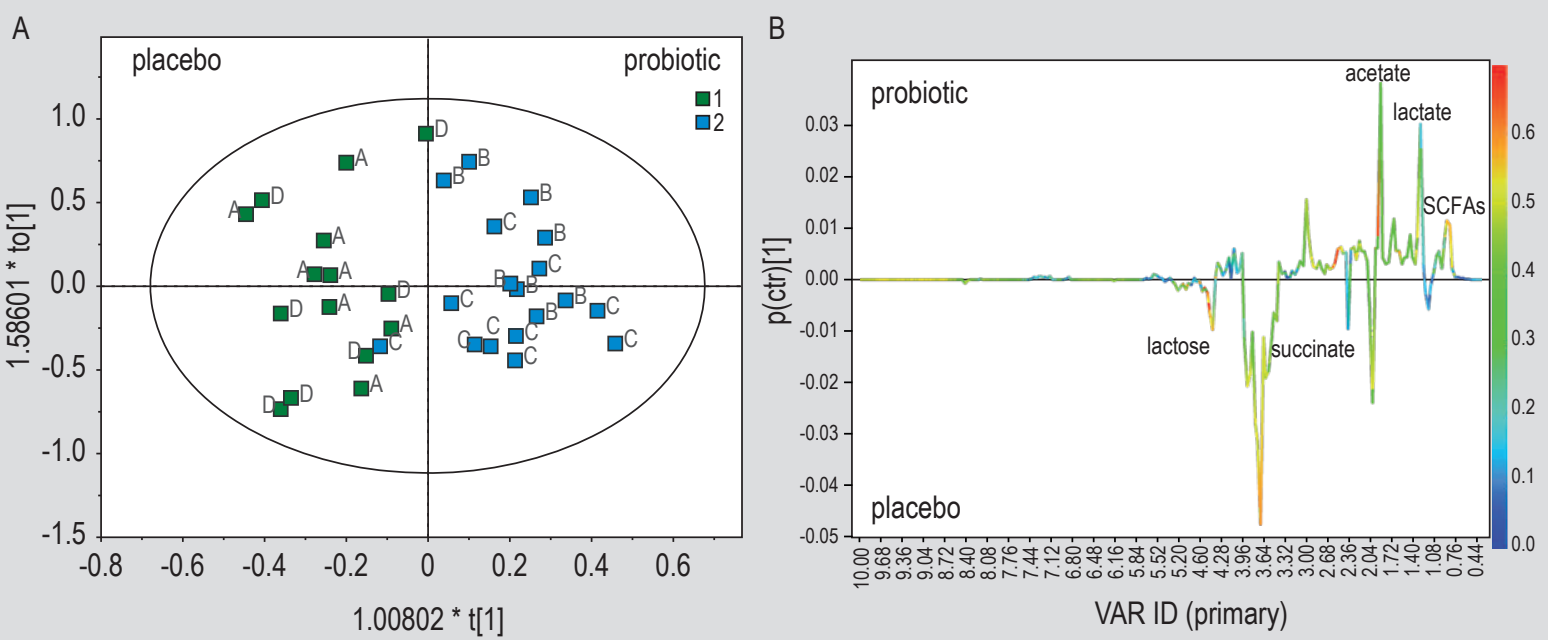

Figure 3. Orthogonal partial least squares-discriminant analysis of faecal samples between placebo group (group $A+D, n=15$, green squares [1]) and probiotic group (group $B+C, n=18$, blue squares [2]). (A) Scatter plot; (B) $S$-line plot. $R^{2} Y=0.748, Q^{2} Y=0.296$.

eczema. Sandin et al. (2009) have shown before that children with positive skin prick tests and allergic symptoms during the first four years of life, also revealed lower levels of SCFAs preceding the clinical manifestation of allergy.

Allergic diseases can be regarded as Th2 immune-mediated diseases in which regulatory T-cell function is impaired (Fishbein and Fuleihan, 2012). Regulatory T-cells therefore are a major target for preventive or therapeutic intervention. Recent data indicate that SCFAs, in particular butyrate and acetate, can directly promote regulatory $\mathrm{T}$-cell generation in the colon of mice (Arpaia et al., 2013; Furusawa et al., 2013). Thus, differences in faecal SCFAs levels of infants who did and did not develop eczema could provide the missing link between gut microbiota, the mucosal immune system and the development of eczema. Elucidating the role of SCFAs could also lead to a better understanding of the biological mechanism for functional effects of probiotic bacteria.

Our data indicate that early life supplementation of specifically selected probiotic strains might influence SFCA production, including butyrate. In model systems of the human gut it has been shown that certain probiotics and synbiotics can influence SCFAs levels (Van Zanten et al., 2012), a finding that supports the data presented here. There are also indications that probiotics can increase the amounts of SCFAs in healthy adults in vivo, without changing the overall faecal microbiota composition (De Preter et al., 2011; Vitali et al., 2010). On the other hand, another study addressing the effects of Lactobacillus acidophilus 74-2 and B. animalis subsp lactis DGCC 420 on faecal microbiota in healthy adults failed to show any effect on faecal SCFAs levels (Klein et al., 2008). In accordance with that study, no increase of SCFAs could be indicated, as in a mouse model with humanised infant microbiota supplementation with Lactobacillus paracasei NCC2461 and Lactobacillus rhamnosus NCC4007 resulted in a decrease in acetate and butyrate (Martin et al., 2008). However, it is difficult to generalise results of these studies, as the effects of probiotics supplementation, including metabolic effects, can be highly strain-specific.

Naturally, when investigating gut metabolites, composition of and changes in the microbial population are of great importance. This was initially evaluated by MCPC, which is a qualitative analysis based terminal restriction fragment length polymorphism (T-RFLP) analysis (Niers et al., 2009). This analysis showed significantly more frequent colonisation with higher numbers of L. lactis in the probiotic group compared with the placebo group during the first 3 months of life. Moreover, no differences were observed in the first 4 weeks of life in the number of children colonised by bifidobacteria but at the age of 3 months, all children in the probiotic group and $85 \%$ of the placebo group were colonised with bifidobacteria. L. lactis was shown to be present in all faecal samples from the intervention group and in significantly higher amounts, and it was present only in $2 / 8$ samples from the placebo group. Bifidobacterium spp. were present in all of the individuals in high numbers (Niers et al., 2009). The overall microbiota composition did not show major differences (Niers et al., 2009; Rutten et al., 2015).

We hypothesise the observed difference in SCFA production most probably is indirect, as none of the probiotic strains included in the used probiotic product is a butyrate producer itself. How this effect is induced cannot be concluded directly from our data. It could be affected by upregulation of the number of butyrate-producing bacteria in the gastrointestinal tract or by increased metabolic activity in general. The main limitation of this study was the small sample size. However, even with these small 
numbers of participants, differences between groups could be demonstrated. Based on the data presented here, a suggested mechanism could be that colonic regulatory T-cell development is impaired when SCFA production by gut microbiota is reduced. This mechanism then may contribute to the development of allergic disease. This specific combination of probiotics might then have the capacity to modulate the metabolic activity of resident gut microbiota for producing higher concentrations of SCFAs. The SCFAs, in particular butyrate, diffuse through gut epithelial cells, stimulating the differentiation of naive $\mathrm{T}$-cells into regulatory $\mathrm{T}$-cells, thereby preventing allergy.

Succinate, lactate and alanine were found to be more abundant in the non-eczema group, whereas glucose, galactose and lactose (sugars) were more prevalent in the eczema group. It can be hypothesised that the higher amounts of different sugar metabolites in the eczema group are caused by decreased absorption of these metabolites in the intestine. Children with eczema are known to have an impaired intestinal mucosal barrier, which could lead to decreased absorption (Rosenfeldt et al., 2004). A comparable finding was observed in faecal extracts of patients with ulcerative colitis compared with healthy controls, as glucose levels were higher in diseased patients (Le Gall et al., 2011). The roles these metabolites play in the development of eczema remain unclear, but do warrant further investigation.

In conclusion, our study suggests a role for intestinal SCFAs in the development of eczema in early life. Group enlargement in comparable studies addressing primary prevention of atopic disease, by supplementation of pre- or probiotics, can strengthen the understanding of possible working mechanisms. Moreover, it can lead to rational development of sustainable microbiota management for prevention and treatment of allergy and other immune mediated diseases, where the production of specific metabolites would be the leading criterion for selection.

\section{Acknowledgements}

This research was supported financially by the Netherlands Enterprise Agency (Agentschap NL, nowadays RVO, formerly SenterNovem), grant number FND06015, and by Winclove Probiotics. We thank Dr. E. Wilson for reviewing the manuscript.

\section{Conflict of interest}

H.K. Kim, I. Besseling-van der Vaart and S. van Hemert are employees of Winclove Probiotics. Winclove Probiotics produces and markets Ecologic ${ }^{\oplus}$ Panda. These authors have no direct or additional financial interests. The other authors do not have conflicts of interest to declare.

\section{References}

Abrahamsson, T.R., Jakobsson, H.E., Andersson, A.F., Bjorksten, B., Engstrand, L. and Jenmalm, M.C., 2014. Low gut microbiota diversity in early infancy precedes asthma at school age. Clinical and Experimental Allergy 44: 842-850.

Arpaia, N., Campbell, C., Fan, X., Dikiy, S., Van der Veeken, J., De Roos, P., Liu, H., Cross, J.R., Pfeffer, K., Coffer, P.J. and Rudensky, A.Y., 2013. Metabolites produced by commensal bacteria promote peripheral regulatory T-cell generation. Nature 504: 451-455.

Azad, M.B., Coneys, J.G., Kozyrskyj, A.L., Field, C.J., Ramsey, C.D., Becker, A.B., Friesen, C., Abou-Setta, A.M. and Zarychanski, R., 2013. Probiotic supplementation during pregnancy or infancy for the prevention of asthma and wheeze: systematic review and metaanalysis. BMJ 347: f6471.

Bisgaard, H., Li, N., Bonnelykke, K., Chawes, B.L., Skov, T., PaludanMuller, G., Stokholm, J., Smith, B. and Krogfelt, K.A., 2011. Reduced diversity of the intestinal microbiota during infancy is associated with increased risk of allergic disease at school age. Journal of Allergy and Clinical Immunology 128: 646-652 e641-645.

Bjorksten, B., Sepp, E., Julge, K., Voor, T. and Mikelsaar, M., 2001. Allergy development and the intestinal microflora during the first year of life. Journal of Allergy and Clinical Immunology 108: 516-520.

Bottcher, M.F., Nordin, E.K., Sandin, A., Midtvedt, T. and Bjorksten, B., 2000. Microflora-associated characteristics in faeces from allergic and nonallergic infants. Clinical and Experimental Allergy 30: 1590-1596.

Brennan, L., 2008. Session 2: Personalised nutrition. Metabolomic applications in nutritional research. Proceedings of the Nutrition Society 67: 404-408.

Bylesjo, M., Rantalainen, M., Cloarec, O., Nicholson, J.K., Holmes, E. and Trygg, J., 2006. OPLS discriminant analysis: combining the strengths of PLS-DA and SIMCA classification. Journal of Chemometrics 20: 341-351.

De Preter, V., Ghebretinsae, A.H., Abrahantes, J.C., Windey, K., Rutgeerts, P. and Verbeke, K., 2011. Impact of the synbiotic combination of Lactobacillus casei shirota and oligofructoseenriched inulin on the fecal volatile metabolite profile in healthy subjects. Molecular Nutrition and Food Research 55: 714-722.

Elazab, N., Mendy, A., Gasana, J., Vieira, E.R., Quizon, A. and Forno, E., 2013. Probiotic Administration in Early Life, Atopy, and Asthma: A Meta-analysis of Clinical Trials. Pediatrics 132: e666-676.

Food and Agriculture Organization of the United Nations/World Health Organization (FAO/WHO), 2001. Evaluation of health and nutritional properties of powder milk and live lactic acid bacteria. Available at: http://tinyurl.com/8bccc3r.

Fishbein, A.B. and Fuleihan, R.L., 2012. The hygiene hypothesis revisited: does exposure to infectious agents protect us from allergy? Current Opinion in Pediatrics 24: 98-102.

Floch, M.H., Walker, W.A., Madsen, K., Sanders, M.E., Macfarlane, G.T., Flint, H.J., Dieleman, L.A., Ringel, Y., Guandalini, S., Kelly, C.P. and Brandt, L.J., 2011. Recommendations for probiotic use-2011 update. Journal of Clinical Gastroenterology 45 Suppl: S168-171. 
Furusawa, Y., Obata, Y., Fukuda, S., Endo, T.A., Nakato, G., Takahashi, D., Nakanishi, Y., Uetake, C., Kato, K., Kato, T., Takahashi, M., Fukuda, N.N., Murakami, S., Miyauchi, E., Hino, S., Atarashi, K., Onawa, S., Fujimura, Y., Lockett, T., Clarke, J.M., Topping, D.L., Tomita, M., Hori, S., Ohara, O., Morita, T., Koseki, H., Kikuchi, J., Honda, K., Hase, K. and Ohno, H., 2013. Commensal microbederived butyrate induces the differentiation of colonic regulatory T cells. Nature 504: 446-450.

Gorissen, D.M., Rutten, N.B., Oostermeijer, C.M., Niers, L.E., Hoekstra, M.O., Rijkers, G.T. and van der Ent, C.K., 2014. Preventive effects of selected probiotic strains on the development of asthma and allergic rhinitis in childhood. The Panda study. Clinical and Experimental Allergy 44: 1431-1433.

Hill, C., Guarner, F., Reid, G., Gibson, G.R., Merenstein, D.J., Pot, B., Morelli, L., Canani, R.B., Flint, H.J., Salminen, S., Calder, P.C. and Sanders, M.E., 2014. Expert consensus document: the International Scientific Association for Probiotics and Prebiotics consensus statement on the scope and appropriate use of the term probiotic. Nature Reviews Gastroenterology and Hepatology 11: 506-514.

Ismail, I.H., Licciardi, P.V. and Tang, M.L., 2013. Probiotic effects in allergic disease. Journal of Paediatrics and Child Health 49: 709-715. Jacobs, D.M., Deltimple, N., Van Velzen, E., Van Dorsten, F.A., Bingham, M., Vaughan, E.E. and Van Duynhoven, J., 2008. ${ }^{1} \mathrm{H}$ NMR metabolite profiling of feces as a tool to assess the impact of nutrition on the human microbiome. NMR in Biomedicine 21: 615-626.

Klein, A., Friedrich, U., Vogelsang, H. and Jahreis, G., 2008. Lactobacillus acidophilus 74-2 and Bifidobacterium animalis subsp lactis DGCC 420 modulate unspecific cellular immune response in healthy adults. European Journal of Clinical Nutrition 62: 584-593.

Kramer, A., Bekeschus, S., Broker, B.M., Schleibinger, H., Razavi, B. and Assadian, O., 2013. Maintaining health by balancing microbial exposure and prevention of infection: the hygiene hypothesis versus the hypothesis of early immune challenge. Journal of Hospital Infection 83 Suppl. 1: S29-S34.

Le Gall, G., Noor, S.O., Ridgway, K., Scovell, L., Jamieson, C., Johnson, I.T., Colquhoun, I.J., Kemsley, E.K. and Narbad, A., 2011. Metabolomics of fecal extracts detects altered metabolic activity of gut microbiota in ulcerative colitis and irritable bowel syndrome. Journal of Proteome Research 10: 4208-4218.

Leonel, A.J. and Alvarez-Leite, J.I., 2012. Butyrate: implications for intestinal function. Current Opinion in Clinical Nutrition and Metabolic Care 15: 474-479.

Lindon, J.C., Holmes, E. and Nicholson, J.K., 2007. Metabonomics in pharmaceutical R\&D. FEBS Journal 274: 1140-1151.

Marchesi, J.R., Holmes, E., Khan, F., Kochhar, S., Scanlan, P., Shanahan, F., Wilson, I.D. and Wang, Y., 2007. Rapid and noninvasive metabonomic characterization of inflammatory bowel disease. Journal of Proteome Research 6: 546-551.

Martin, F.P., Wang, Y., Sprenger, N., Yap, I.K., Lundstedt, T., Lek, P., Rezzi, S., Ramadan, Z., Van Bladeren, P., Fay, L.B., Kochhar, S., Lindon, J.C., Holmes, E. and Nicholson, J.K., 2008. Probiotic modulation of symbiotic gut microbial-host metabolic interactions in a humanized microbiome mouse model. Molecular Systems Biology 4: 157.

Monleon, D., Morales, J.M., Barrasa, A., Lopez, J.A., Vazquez, C. and Celda, B., 2009. Metabolite profiling of fecal water extracts from human colorectal cancer. NMR in Biomedicine 22: 342-348.
Nicholson, J.K., Holmes, E. and Wilson, I.D., 2005. Gut microorganisms, mammalian metabolism and personalized health care. Nature Reviews Microbiology 3: 431-438.

Niers, L., Martin, R., Rijkers, G., Sengers, F., Timmerman, H., Van Uden, N., Smidt, H., Kimpen, J. and Hoekstra, M., 2009. The effects of selected probiotic strains on the development of eczema (the PandA study). Allergy 64: 1349-1358.

Niers, L.E., Hoekstra, M.O., Timmerman, H.M., Van Uden, N.O., De Graaf, P.M., Smits, H.H., Kimpen, J.L. and Rijkers, G.T., 2007. Selection of probiotic bacteria for prevention of allergic diseases: immunomodulation of neonatal dendritic cells. Clinical and Experimental Immunology 149: 344-352.

Nylund, L., Nermes, M., Isolauri, E., Salminen, S., De Vos, W.M. and Satokari, R., 2015. Severity of atopic disease inversely correlates with intestinal microbiota diversity and butyrate-producing bacteria. Allergy 70: 241-244.

Panduru, M., Panduru, N.M., Salavastru, C.M. and Tiplica, G.S., 2015. Probiotics and primary prevention of atopic dermatitis: a metaanalysis of randomized controlled studies. Journal of the European Academy of Dermatology and Venereology 29: 232-242.

Quigley, E.M., 2013. Gut bacteria in health and disease. Gastroenterology and Hepatology 9: 560-569.

Rosenfeldt, V., Benfeldt, E., Valerius, N.H., Paerregaard, A. and Michaelsen, K.F., 2004. Effect of probiotics on gastrointestinal symptoms and small intestinal permeability in children with atopic dermatitis. Journal of Pediatrics 145: 612-616.

Rutten, N.B.M.M., Gorissen, D.M.W., Eck, A., Niers, L.E.M., Vlieger, A.M., Besseling-van der Vaart, I., Budding, A.E., Savelkoul, P.H.M., Van der Ent, C.K. and Rijkers, G.T., 2015. Long term development of gut microbiota composition in atopic children: impact of probiotics. PLoS ONE 10: e0137681.

Sanders, M.E., Guarner, F., Guerrant, R., Holt, P.R., Quigley, E.M., Sartor, R.B., Sherman, P.M. and Mayer, E.A., 2013. An update on the use and investigation of probiotics in health and disease. Gut 62: 787-796.

Sandin, A., Braback, L., Norin, E. and Bjorksten, B., 2009. Faecal short chain fatty acid pattern and allergy in early childhood. Acta Paediatrica 98: 823-827.

Topping, D.L. and Clifton, P.M., 2001. Short-chain fatty acids and human colonic function: roles of resistant starch and nonstarch polysaccharides. Physiological Reviews 81: 1031-1064.

Van Zanten, G.C., Knudsen, A., Roytio, H., Forssten, S., Lawther, M., Blennow, A., Lahtinen, S.J., Jakobsen, M., Svensson, B. and Jespersen, L., 2012. The effect of selected synbiotics on microbial composition and short-chain fatty acid production in a model system of the human colon. PloS One 7: e47212.

Vitali, B., Ndagijimana, M., Cruciani, F., Carnevali, P., Candela, M., Guerzoni, M.E. and Brigidi, P., 2010. Impact of a synbiotic food on the gut microbial ecology and metabolic profiles. BMC Microbiology 10: 4 .

Yen, S., McDonald, J.A., Schroeter, K., Oliphant, K., Sokolenko, S., Blondeel, E.J., Allen-Vercoe, E. and Aucoin, M.G., 2015. Metabolomic analysis of human fecal microbiota: a comparison of feces-derived communities and defined mixed communities. Journal of Proteome Research 14: 1472-1482. 